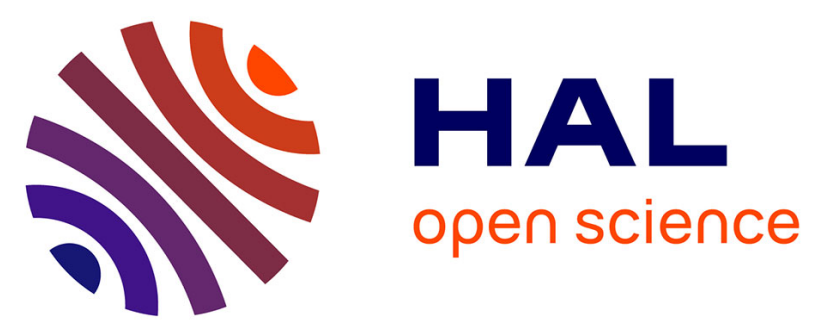

\title{
Preparing a Smart Environment to Decision-Making in Emergency Traffic Control Management
}

\author{
Jacimar F. Tavares, Marcos Borges, Adriana S. Vivacqua
}

\section{To cite this version:}

Jacimar F. Tavares, Marcos Borges, Adriana S. Vivacqua. Preparing a Smart Environment to DecisionMaking in Emergency Traffic Control Management. 3rd International Conference on Information Technology in Disaster Risk Reduction (ITDRR), Sep 2018, Poznan, Poland. pp.12-21, 10.1007/9783-030-32169-7_2. hal-02799281

\section{HAL Id: hal-02799281 \\ https://hal.inria.fr/hal-02799281}

Submitted on 8 Jun 2020

HAL is a multi-disciplinary open access archive for the deposit and dissemination of scientific research documents, whether they are published or not. The documents may come from teaching and research institutions in France or abroad, or from public or private research centers.
L'archive ouverte pluridisciplinaire HAL, est destinée au dépôt et à la diffusion de documents scientifiques de niveau recherche, publiés ou non, émanant des établissements d'enseignement et de recherche français ou étrangers, des laboratoires publics ou privés. 


\title{
Preparing a Smart Environment to Decision-Making in Emergency Traffic Control Management
}

\author{
Jacimar F. Tavares, Marcos R.S. Borges and Adriana S. Vivacqua \\ Programa de Pós Graduação em Informática, Departamento de Ciência da Computação, \\ Instituto de Matemática, Universidade Federal do Rio de Janeiro, Rio de Janeiro, Brazil \\ jacimar.tavares@gmail.com, mborges@ppgi.ufrj.br, \\ avivacquaedcc.ufrj.br
}

\begin{abstract}
This work addresses the smart environments theme and presents a framework for decision making based on information from an important Brazilian city, which have technologies used in the preparation, monitoring and management of traffic emergencies. The technological resources that the city has are exposed, as well as statistical data showing a panorama of traffic in recent years. The technologies analyzed in the context of the framework are useful in decisions-making, thus creating an environment capable of acquiring knowledge about all those who are involved in it (its inhabitants and everything that surrounds them) and applying the knowledge, adapting it to the monitoring, in the emergency preparedness. Also, simulations of scenarios that could be constructed were presented if new components were inserted in the environment or if there were specific data for a purpose. Such simulations guide future efforts to improve the environment and to improve activities relevant to the day-to-day traffic of cities
\end{abstract}

Keywords: Smart environments, Framework, Emergencies, Decision-making.

\section{Introduction}

The technological evolution that the world has experienced in recent years has increasingly demonstrated the need to establish connections between people, be it through networks such as the internet or through devices connected in local networks. Smart environments have increasingly incorporated such technologies by linking devices in order to perform daily tasks, which is possible thanks to the possibility of collaboration between devices [1]. The establishment of an smart environment will be subject to the needs of obtaining differentiated experiences, according to the context where it is inserted and according to the needs of those involved.

Smart Environments act in certain contexts. Such contexts are defined by a set of information that characterizes it, making clear its current situation, being it refers to entities as places, objects or people. The context can make clear from the characteristics of the people or objects contained in it to its geographic, spatial or even climatological information [2]. The context addressed in this work, where the smart environment 
explored is inserted, is the management of emergencies arising from recorded traffic incidents.

It refers to Smart Environments [3] as being the environment capable of acquiring knowledge about all those who are involved in it (its inhabitants and everything that surrounds them) and apply knowledge, also in its stakeholders and everything that surrounds them. With it, is possible to achieve the goal of adapting the environment to its stakeholders, efficiently and generating a sense of comfort. In the context of this work it is possible to visualize that the data generated by the smart environment explored here serve as the basis for decision make for those involved in traffic incidents recorded thanks to the support of the environment.

Aware of the issues surrounding the definition of a smart environment, it can be said that they are useful in the decision-making process. Decision-making is understood as the decision-making process in which each of the parties involved can, through the analysis of information and scenario possibilities, define actions to be taken, in an agile way, aiming to achieve some specific objective of the organization in which it is inserted [4].

The research question to be answered in this paper is: considering the existence of technological resources that allow the monitoring, recording and processing of information on traffic emergencies, it is possible to create a mechanism that allows decision making as Do the incidents occur in traffic? The proposal of this work is to create and present a framework that, when used in the management of traffic emergencies, allows those involved to make decisions. It is argued that the decisions that can be taken in the context of the framework are capable of directly impacting on the day-to-day of those involved in the traffic of the citizens, such as mobility professionals, health agents and the population that moves around the city, therefore, the framework developed aims to support decision making during the occurrence of an accident, making the urban mobility can adapt to the scenario found at the time, in the environment.

This paper is defined as follows: Section 2 provides information about the technological features of the environment being explored in this paper. It is a Brazilian branch of the municipal public sphere, the city of Porto Alegre (in Rio Grande do Sul), whose traffic data is openly available on the internet. Section 3 presents the data and contextualizes them, allowing the analysis of the current scenario of the traffic of said municipality. The presentation will use visualizations from the ViaPOA tool, a data analyzer that generates summary views with different graphical representations by combining different visualization techniques.

Section 4 aims to promote discussion about how certain technologies, combined in an Smart environment, can be useful in decision-making for the definition of alternatives to traffic emergencies as soon as they occur. In this sense, the framework developed in the context of this work will be presented. Finally, section 5 presents the final considerations and future work. At the end, a scenario simulation is presented aiming to show possibilities of gains in the management of emergencies, if a certain technology were present within the ambit of the proposed Smart environment. 


\section{Current scenario of the City- Technological Resources}

In the context of this work, information was collected regarding issues such as technological resources used in the management and monitoring of emergencies related to traffic incidents. The information collected belongs to the city of Porto Alegre, capital of the Brazilian state of Rio Grande do Sul, with an estimated population of 1.5 million people, according to the IBGE survey, in 2017 [5]. Its transit is managed by the Public Company of Transport and Circulation - EPTC. Such a company aims to adopt activities that can directly impact on the task of making municipal transit increasingly safe [6].

Records of traffic incidents are made in a registration system for this purpose. They are also data made available openly on the internet, showing a history of data stored from the year 2000 up to 2017 (with parts of 2018) [7].

The actions of planning, supervision and education of the transit, which are carried out by the managers, are based on information generated by the body and those responsible for the day to day traffic. The sources can be the most diverse, such as registration in loco, by the agents of traffic, even via camera monitoring of the ways and data coming from social networks.

There is also the Central Control and Monitoring of Mobility (CECOMM) [8], which aims to manage urban mobility in major transportation routes and routes, with features such as video monitoring system, which, in an integrated way, captures, records and visualizes images of remote surveillance cameras, forwarding them to the team responsible for the occurrence; Tracking of the Taxi and Loads Fleet, which aims to monitor in real time the provision of the services of the public fleets, as well as their locations; Communication via Radio, which aims to establish another channel for the exchange of information among professionals involved in the environment; Control of the Traffic Network in a centralized way, allowing the professionals involved to act as needed, with remote and online service of the traffic light network, aiming to promote changes in the normal flow of the semipalams, whenever any event demands; and Monitoring of urban collective transportation, allowing monitoring and control of the operations carried out by the collectives, in real time.

The Mobility Monitoring and Control Center has a control room that operates 24 hours a day, 7 days a week. Panels are used to visualize, in real time, some of the city's major thoroughfares (Figure 1) as part of constant surveillance for immediate interference as needed.

The diversity of technological resources of the public agency is focused on changing urban mobility in search of safer traffic, the largest source of data being the Traffic Accident Registration System maintained by EPTC. In the context of the current scenario, it is necessary that the data obtained at the moment the traffic accident events occur are recorded so that strategies are later traced, such as statistical analysis, to generate information that is used in the improvement mobility. 


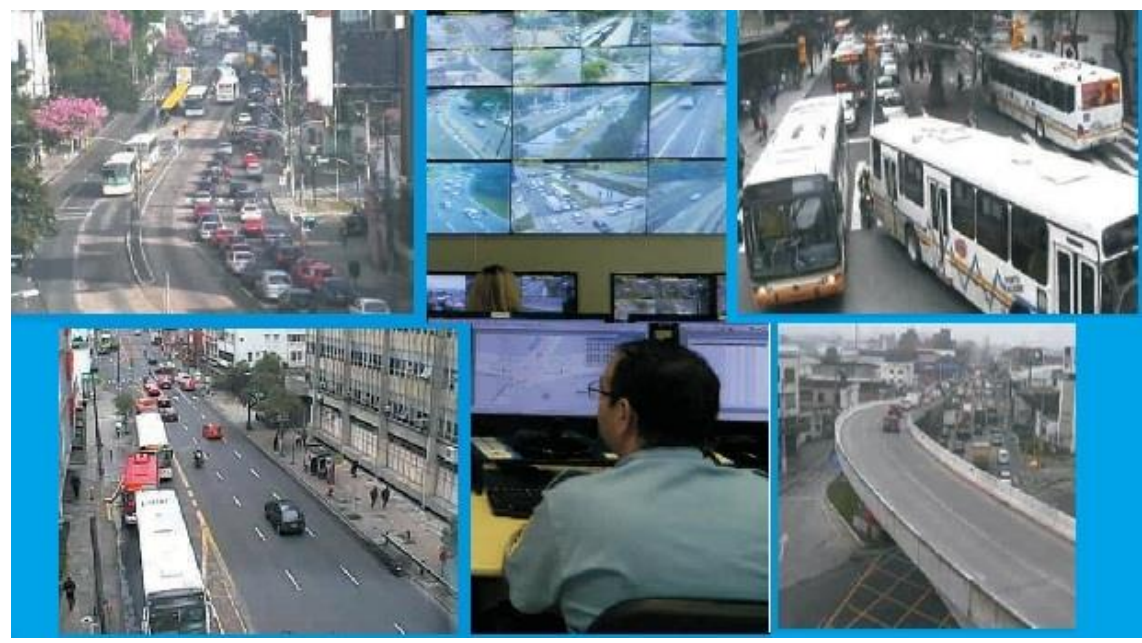

Fig. 1. Monitoring cameras and their respective views. Source: EPTC website.

\section{Traffic Accidents Historical Data Analysis}

In this section are presented historical data about the traffic that were raised by the municipal body and made available free of charge and open on the internet [9]. These data are currently used in planning actions that aim to improve the urban mobility of the city. Figure 2 shows the statistical dashboard of the ViaPOA tool, developed especially as part of this work, so that it was possible to statistically analyze the data collected, as well as the visual representation of the results.

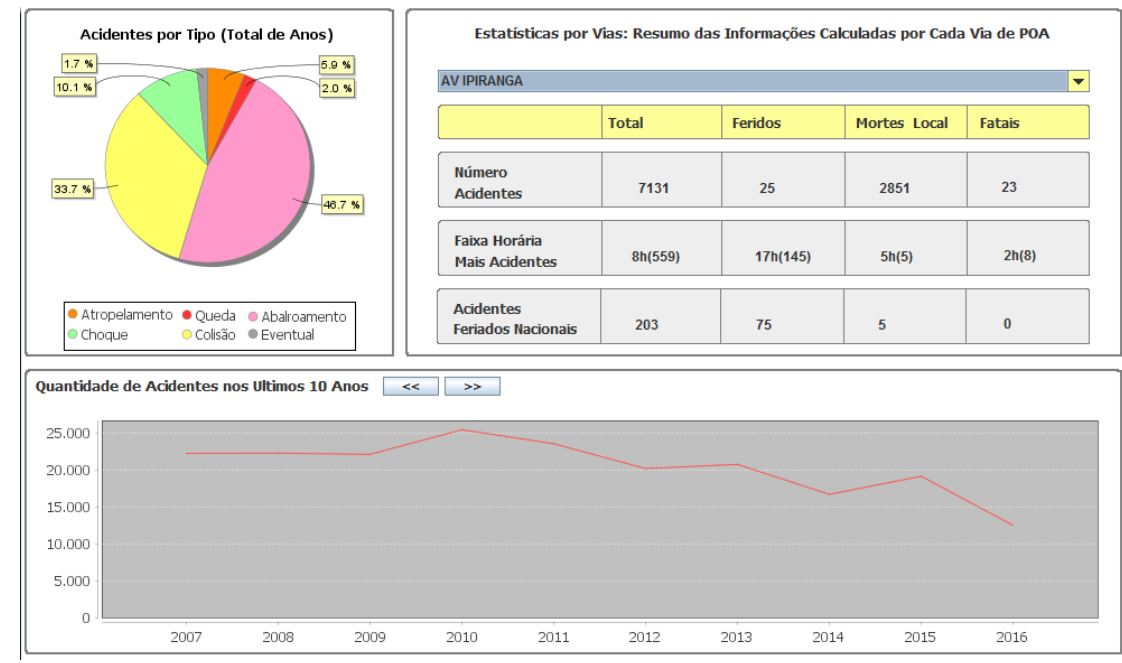

Fig. 2. ViaPOA Statistical Dashboard 
The sum of accidents in the years 2000 to 2016 shows that collision was the most common type of accident on the roads of the city. Other types of accidents recorded are collisions, vehicle collisions, run-ins, falling vehicles in ditches and other places, as well as other types of accidents reported as incidental. The number of accidents in the last 10 years can be measured and their evolution seen. From 2007 to 2016, there is a drop in the number of accidents, which can be attributed, among other things, to improving urban mobility and traffic awareness campaigns. Figure 3 shows summaries of data grouped by categories.

Analyzing Figure 3 it is possible to notice that the greater of the accidents occurred in crossings. The hourly range that most occurred was the afternoon part, including the hours of noon at six in the afternoon. It is also worth noting that in most accidents the climate situation at the time was classified as good.

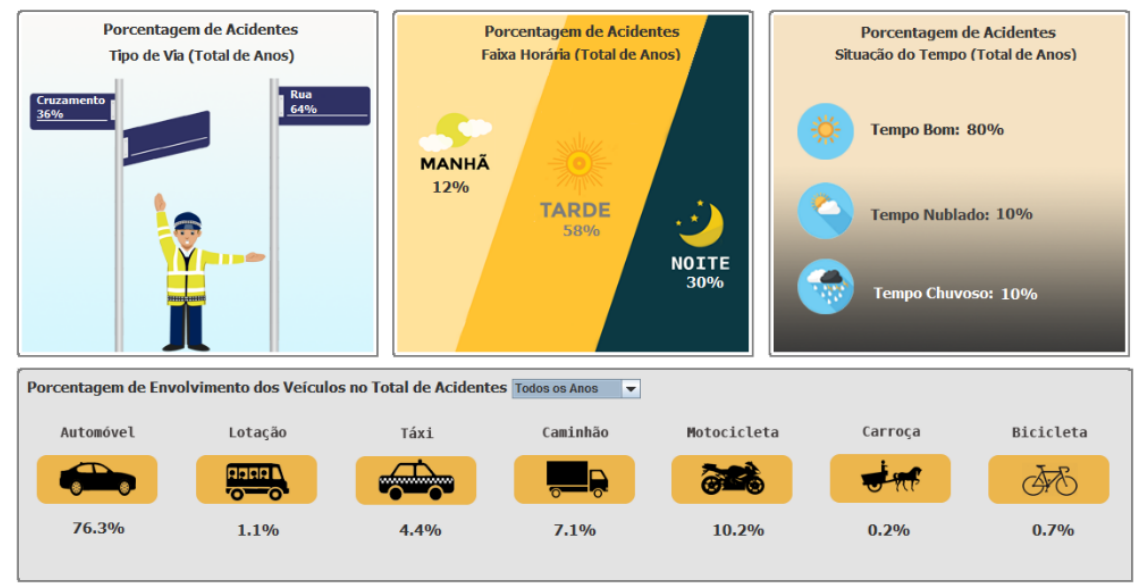

Fig. 3. ViaPOA Dashboard groups.

Considering all the data analyzed in the context of this work, it was possible to notice that in $76 \%$ of the accidents accidents involved cars, followed by $10.2 \%$ of the times involving motorcycles. Other vehicles were involved in accidents, such as parking lots $(1.1 \%)$, taxis $(4.4 \%)$, trucks $(7.1 \%)$, wagons $(0.2 \%)$ and bicycles $(0.7 \%)$.

It is important to note that the data analyzed here has undergone a filtering process to remove records that have generated problems in the data export and non-standard layout records defined for export. In this case, the reliable result may vary in relation to the data contained in the database of said municipality, which does not impair the statistical mechanisms implemented to analyze the traffic data situation of recent years.

\section{Developed Framework and the simulations of scenarios of evolution of the Smart Environment}

The historical data analysis presented in Section 3 aimed to demonstrate an overview of the data and statistics that can be generated through the use of the ViaPOA tool, 
automatically, however, it is important to highlight that the ViaPOA tool is not yet part of the day-to-day management of emergencies in the municipality, and the task of analyzing the statistical data is not supported by such tool. As discussed, actions aimed at improving mobility and management of traffic emergencies are taken by analyzing the historical data after its registration, but even considering the use of the ViaPOA tool, it would still not be enough for decisions to be taken in a way guided by some automated strategy, since ViaPOA does not suggest guided ways to avoid a solution, given a certain scenario characterized. Moreover, a posteriori decisions can only be made on the basis of statistical analyzes and based on the experience of those involved in the management of traffic emergencies, since there is no mechanism to guide those involved in decision making by characterizing an event occurred at the same time, although the analyzed municipality has technological resources such as monitoring cameras, active and active social networks, telephone contact channels, and central and local traffic agents.

Based on this, this section aims to promote the discussion about how certain technologies, combined for decision making, can determine actions to be taken immediately, making variations of the traffic itself generate information that allows the environment to adapt to life of those involved in traffic, as events occur and are recorded. An Smart environment can allow decision-making to define alternatives for emergencies in transit as soon as they occur [10].

\subsection{Developed Framework and it possible automation}

Decision making becomes necessary from the moment an event occurs in traffic, which can be an accident or a sudden illness that occurred with some citizen in the day to day traffic of the municipality. Figure 4 illustrates the framework developed.

The possible decisions that can be made depend on the type of professional perceiving the event. As an example we can mention the professionals of the Mobility Monitoring Center, who become aware of the events using resources such as telephone (incoming calls), surveillance cameras, social media and tele-news; First responders, whose emergency service can be activated directly by the population through telephone contact; and the Traffic Agents, who are professionals working on the day-to-day of traffic, observing and giving the correct route to the events occurred in traffic. In social networks, it is known that collective knowledge [11] that can be generated about a given emergency can be useful in quickly understanding the facts, because it considers the massive participation of people who freely collaborate by sharing information in their social networks.

In the context of this work, it is argued that sensors can contribute to the generation of information to be interpreted by professionals responsible for decision making. It is worth noting that the collection of information through monitoring of environments (in the context of this work, monitoring of roads and public places, such as collectives) with microsensors allows the collection of data for long periods. Direct contact of sensor nodes in a network, for example, with their environment allows each of the nodes to provide detailed data and measurements that are not easily obtained without them [12]. 


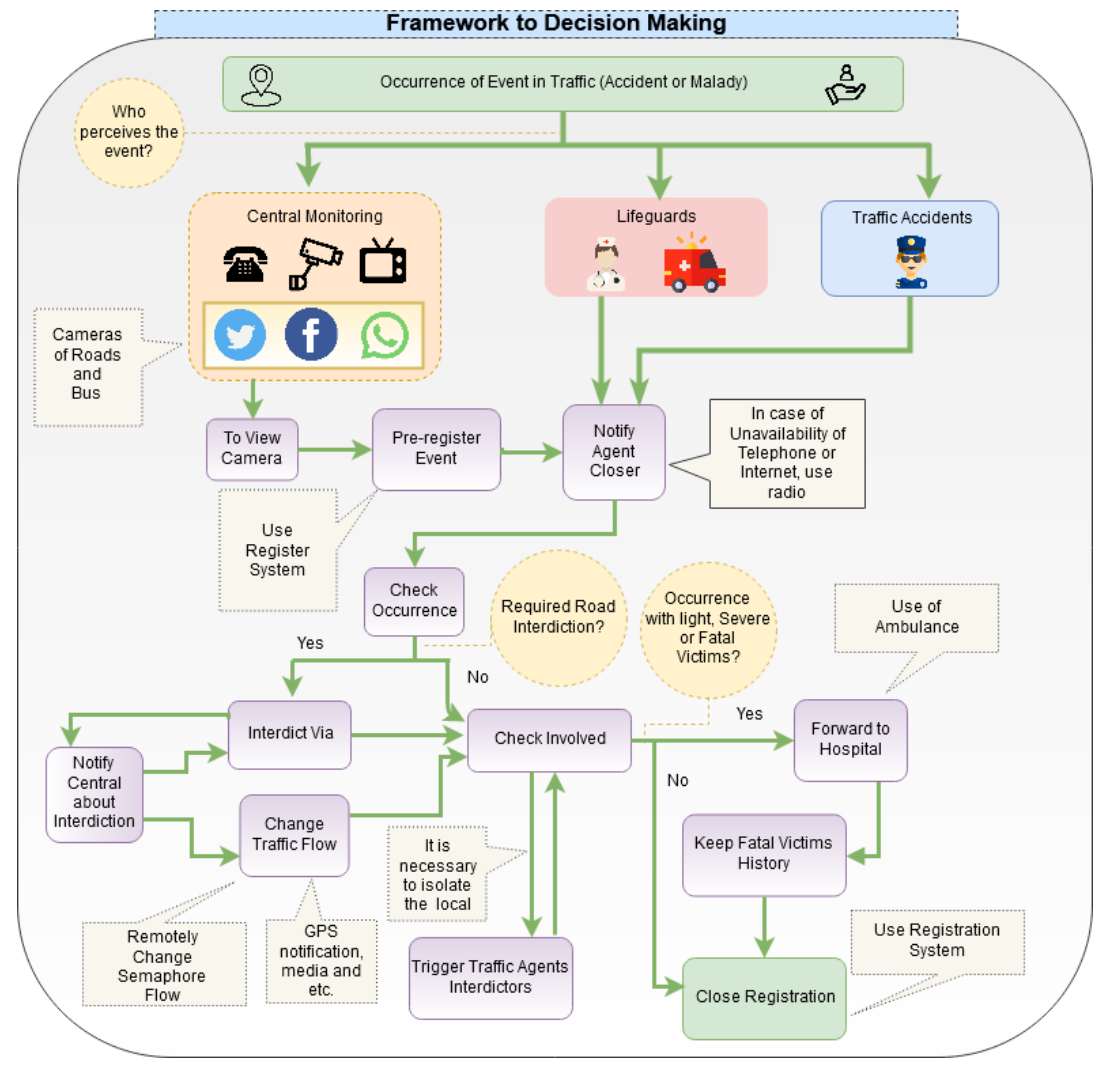

Fig. 4. Framework

Due to the great extension of the roads of a municipality it is necessary that the connection between the sensors of a network is made through wireless connections. Wireless networks can span hundreds and thousands of nodes that act in a selforganized and fault-tolerant manner [13].

In checking the occurrence (Figure 4) it may be necessary to have to interdict the path where the event occurred. If necessary, the route is forbidden and the situation of those involved in the event is verified. The agent notifies the central of the interdiction and it does it, changing, in parallel, the traffic flow, remotely, generating new configurations for the semaphore network of the region. The change in the flow should generate notifications in the GPS, Social Media and others, like press organs making vehicles that are transiting in the region can have their paths changed automatically.

The verification of those involved allows the victims to be sent to the hospital or health unit, while still keeping the history of the victims, to compile statistics of victims who did not die at the time of the accident, but later.

The flows described in the framework contemplate the use of existing technologies within the municipality. The framework presents itself as a way of guiding decisionmaking, constituting an intelligent environment capable of altering the daily life of those involved in the transit, whether they are public professionals, victims or persons 
who would otherwise be impacted by the occurrence of the event and by the decision made, as drivers who travel through the region of the event.

As a contribution of this work, functionalities are discussed for an intelligent environment capable of automating the tasks of decision making.

The automation of the calculation of the opening and closing time duration of the semaphore semaphores is made possible by obtaining the data mentioned in section 3 . Notifications of programmed stoppages and stops can be generated automatically and sent to the GPS of vehicles in transit, or preparing to enter it. In this sense, a transit agent (on-site or in the Monitoring Center) or a rescuer could emit, via smart phone, a prohibition signal that would be triggered for the vehicles near the region of the event.

When it is considered that an emergency situation can lead to material and immaterial damages, to the victims and to the environment, it is concluded that the attempt to reduce the impacts caused by the emergency can be better conducted if there is coordination of different factors that include team experience, infrastructure for emergency response, training and team planning [14].

In another aspect, in order to maintain the history of fatalities after the accident (deaths within 30 days after the accident), the doctors of the hospital that received the victims could insert in an application the data of the confirmed event, thus completing the of the occurrence of traffic. Already in the need to trigger an ambulance, a traffic agent should consult an application on your smartphone that will allow you to notify the nearest, issuing emergency alert, if any.

\section{Conclusions}

This work contextualized intelligent environments as the environment capable of acquiring knowledge about all those who are involved in it (its inhabitants and everything that surrounds them) and apply the knowledge, also in its stakeholders and everything that surrounds them, adapting the environment to its stakeholders. The present technologies were presented in the scope of an important Brazilian municipality, Porto Alegre. These technologies allowed the definition of a framework that assists decision making in the management of traffic emergencies. It was argued that the set of technologies used in the framework constitute an intelligent environment capable of adapting the traffic to the reality of recorded incidents in any moment, in analysis at the moment.

As future work, it is intended to develop the specified tool, which will be able to automate decision making by making the environment automatically adapt to the occurrence of an event. In this sense it would be possible to remove, for example, manual steps involving people, in generating GPS notifications. By automating this step, it would be possible to generate the notification as soon as the accident event was soon registered in the database. A possible scenario that could be exploited in the context of the framework is what would involve historical data from GPS systems such as Google Maps and Waze. In a decision-making process, you can create block notifications of routes that are impacted by the event within a given time. A context that could be exploited by the framework would be the programming of the traffic light 
network through past events. This would be possible if there were historical data of occurrence of geolocated events in a database. Data such as track, block type, start time of the block, closing time of the block, total duration, kilometers of slowness in the nearby roads and in the roads where the event occurred, would automatically allow the length of time for open or closed semi- adjusted to meet the demand of that region. Near to those of an accident, for example, could have their opening and closing times changed, aiming at improving the mobility of alternative routes to the occurrence of the event.

\section{Acknowledgements}

The work of Marcos R.S. Borges has been supported by FAPERJ under grant number E-26/202.876/2018.

\section{References}

1. Das, S.K., Cook, D.J.: Designing Smart Environments: A Paradigm Based on Learning and Prediction. In: Pal S.K., Bandyopadhyay S., Biswas S. (eds) Pattern Recognition and Machine Intelligence. PReMI 2005, LNCS, vol. 3776, Springer, Berlin, Heidelberg (2005).

2. Dey, A., Abowd, G. D., Salber, D.: A context-based infrastructure for smart environments. Tech. Rep. 1999, http://www.cc.gatech.edu/fce/contexttoolkit/pubs/MANSE99.pdf.

3. Cook, D.J., Youngblood, G.M., Das, S.K.: A Multi-Agent Approach to Controlling a Smart Environment. AI and Smart Homes, 165-182 (2006).

4. Porto, M.A.G, Bandeira, A.A.: O processo decisório nas organizações. (2006). http://www.simpep.feb.unesp.br/anais/anais_13/artigos/980.pdf, last accessed 2018/04/02.

5. IBGE. Brasil em Síntese. População. Disponível em: https://cidades.ibge.gov.br/brasil/rs/porto-alegre/panorama, last accessed 2018/05/01.

6. EPTC. Home page. http://www2.portoalegre.rs.gov.br/eptc, last accessed 2018/05/02.

7. Welcome to \#datapoa. The open data portal of Porto Alegre city. Bem Vindo ao \#datapoa. O portal de dados abertos da cidade de Porto Alegre(in portuguese). O portal de dados abertos da cidade de Porto Alegre. http://datapoa.com.br, last accessed 2018/05/01.

8. EPTC. Central de Controle e Monitoramento da Mobilidade, http://www2.portoalegre.rs.gov.br/eptc/default.php?p_secao=224 last accessed 2018/05/02

9. DataPoa. Traffic Accident, http://datapoa.com.br/dataset/acidentes-de-transito, last accessed 2018/05/02.

10. Santos-González, I, Rivero, A., Caballero-Gil, P., Hernández-Goya, C.: Alternative communication system for emergency situations. WEBIST 2014.

11. Vivacqua, A. S., Borges, M.R.S.: Taking advantage of collective knowledge in emergency response systems. Journal of Network and Computer Applications 35, 189-198 (2012).

12. Mainwaring, A., Culler, D., Polastre, J., Szewczyk, R., Anderson, J.: Wireless sensor networks for habitat monitoring, In: Proceedings of the 1st ACM international workshop on Wireless sensor networks and applications, September 28-28, 2002, Atlanta, Georgia, USA.

13. Oliveira, L., Rodrigues, J. R.: Wireless Sensor Networks: a Survey on Environmental Monitoring. Journal of Communications 6 (2) 143 - 151 (2011).

14. Freitas, D. P., et al.: A Framework for Dealing Collaboratively with Interactions from Social Media in Emergency Situations. In: Proceedings of IEEE International Conference on Computer Supported Cooperative Work in Design, 2017, Wellington, New Zealand. 